\title{
Theoretical Film Cooling Effectiveness Investigation on C3X Vane Suction Side with Multi Trench Configuration
}

\author{
Antar M.M. Abdala \\ Harbin Engineering University, Harbin \\ 150001, China \\ antar451@yahoo.com
}

\author{
Fifi N.M. Elwekeel \\ Harbin Engineering University, Harbin \\ 150001, China \\ fifinew2000@yahoo.com
}

\author{
Qun Zheng \\ Harbin Engineering University, Harbin \\ 150001, China \\ zhengqun@hrbeu.edu.cn
}

\begin{abstract}
In the present work, computational simulations were made using SST turbulence model with Gamma Theta model which available in ANSYS CFX. Multi-trench configuration consists of two trenches together, one wider trench and the other is narrow trench that extruded from the wider one. Multi trench configuration was recessed on $\mathrm{C} 3 \mathrm{X}$ vane suction side. Several blowing ratios in the range (0.5:3) were investigated. The results indicate that this configuration increased adiabatic effectiveness as blowing ratio increased. No observed film blow-off at all blowing ratios.
\end{abstract}

Keywords- Gas turbine; Multi-trench; Film cooling; Adiabatic effectiveness; C3X; Jet interaction phenomena

\section{INTRODUCTION}

Gas turbine blades need to be effectively cooled to increase component life and reduce maintenance costs. With increasing turbine inlet temperatures, modern hot gas path components may be coated with thin layers of thermal barrier coatings (TBC) made of ceramic material, such as Yttria with stabilized Zirconia $\mathrm{Lu}$ et al [1]. Gas turbine efficiency can be significantly increased by cooling technologies. Shaped holes have proven to provide the highest adiabatic effectiveness among film cooling configurations but are expensive to manufacture than configurations of cylindrical holes embedded in transverse trenches. Trench performance is highly dependent on the configuration, so investigating variations in depth, width, and shape is important to maximize trench effectiveness. Several studies have investigated various trench configurations. Bunker [2], Waye and Bogard [3], Lu et al [4] and Harrison and Bogard [5] studied film holes embedded in trenches. Their results showed that the film cooling holes provide higher film effectiveness when embedded in a trench and the narrow trench configuration provided the best adiabatic effectiveness performance. Jia et al [6] investigated film holes with compound angles embedded in trenches. Both $45^{\circ}$ and $90^{\circ}$ compound angles can further enhance the film cooling effectiveness over the axial ejection. Zuniga and Kapat [7] studied effect of increasing pitch-to-diameter ratio on the film cooling effectiveness of shaped and cylindrical holes embedded in trenches. The trenching case has been shown to significantly increase film coverage this study. Albert and Bogard [8] measured film cooling effectiveness on turbine vane pressure side with narrow trench. Their results showed that effectiveness increase with blowing ratio for the showerhead and pressure side trenched hole. The aim from this study is to investigate centerline and lateral adiabatic film effectiveness for film cooling hole embedded in transverse multi trench configuration which recessed on suction side of $\mathrm{C} 3 \mathrm{X}$ vane at different blowing ratios by using CFX 12 .

\section{NOMENCLATURE}

\begin{tabular}{|c|l|}
\hline D & Hole diameter $(\mathrm{m})$ \\
\hline DR & Density ratio of coolant to mainstream, $\rho_{\mathrm{c}} / \rho_{\infty}(-)$ \\
\hline $\mathrm{L}$ & Hole length $(\mathrm{m})$ \\
\hline $\mathrm{M}$ & $\begin{array}{l}\text { Blowing ratio of coolant to mainstream }(-) \\
\mathrm{M}=\mathrm{DR} * \mathrm{U}_{\mathrm{c}} / \mathrm{U}_{\infty}\end{array}$ \\
\hline $\mathrm{P}$ & Hole spacing $(\mathrm{m})$ \\
\hline $\mathrm{S}$ & Trench depth $(\mathrm{m})$ \\
\hline $\mathrm{T}$ & Temperature $(\mathrm{K})$ \\
\hline $\mathrm{Tu}$ & Mainstream turbulence intensity $(\%)$ \\
\hline $\mathrm{W}$ & Trench width $(\mathrm{m})$ \\
\hline $\mathrm{X}$ & Streamwise coordinate along model surface \\
\hline $\mathrm{Y}^{+}$ & Non-dimensional wall distance \\
\hline Greek symbols \\
\hline$\Lambda$ & Turbulence length scale \\
\hline$\alpha$ & Coolant injection angle $($ deg. $)$ \\
\hline$\eta$ & Adiabatic effectiveness, $\left(\mathrm{T}_{\infty}-\mathrm{T}_{\mathrm{aw}}\right) /\left(\mathrm{T}_{\infty}-\mathrm{T}_{\mathrm{c}}\right)$ \\
\hline$\theta$ & Non-dimensional temperature ratio, $\left(\mathrm{T}_{\infty}-\mathrm{T}\right) /\left(\mathrm{T}_{\infty}-\mathrm{T}_{\mathrm{c}}\right)$ \\
\hline$\rho$ & Density $\left(\mathrm{kg} / \mathrm{m}^{3}\right)$ \\
\hline Subscripts \\
\hline$\infty$ & Mainstream \\
\hline aw & Adiabatic wall \\
\hline $\mathrm{c}$ & Coolant \\
\hline
\end{tabular}

\section{COMPUTATION SETUP}

From above mentioned studies, the trench widths are varied between $1.13,1.5,2,3,3.5$ and $4 \mathrm{D}$ and also the depth changed between $0.5,0.75,1$ and $3 \mathrm{D}$. Blowing ratios tested from 0.5 to 4 and the trench edges are changed also. In this study new configuration are used to prevent the jet lift-off and 
possibility to increase the blowing ratio and the same time this configuration maintain the mechanical integrity.

The new configuration is called multi trench. Multi trench configuration consists of two trenches together, one wider trench (4D) and a narrow trench (2D) that extruded from the wider one. The steps heights are changed to $0.5 \mathrm{D}$ and $0.8 \mathrm{D}$ as shown in Fig. 1. For various steps heights with altered the step angles can be used as a recommendation for future works.

An outline of the geometry for the multi trench is shown in Fig. 2. The test vane of current study was approximately 4 times larger than the vane model used by Hylton et al. [9].

Accuracy of solutions is strongly dependent upon the quality of the grid system in minimizing grid-induced errors and in resolving the relevant flow physics. In this study, a grid sensitivity study was carried out to determine the appropriate grid. Fig. 3 illustrates this study for three grids - the baseline grid with 2.1 million cells, a finer grid with 3.5 million cells, and a still finer grid with 4.5 million cells. For the two finer grids, the additional cells were all concentrated about the filmcooling hole and the hot gas/coolant jet interaction region, where the flow physics is most complicated. From this grid sensitivity study, the baseline grid was found to give essentially the same result for the lateral adiabatic effectiveness as those from adaptation 1 and 2 grids. The final mesh of multi trench hole region is shown in Fig. 3 and 3.5 million cells were chosen. Simulation conditions are presented in Table 1. The results obtained in the current study were generated using ANSYS CFX 12 code and SST turbulence model with gamma theta transition model was utilized. A very fine region of cells was created on the walls to approximate $\mathrm{Y}^{+}$ values less than unity. The convergence criterion was set to RMS residuals of $1 * 10^{-5}$.

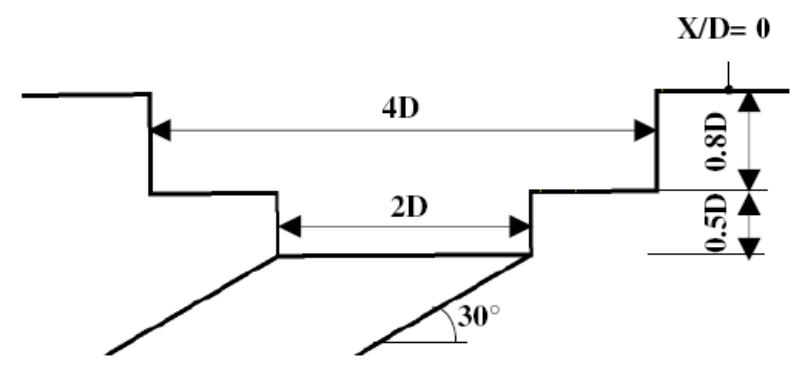

Figure 1 Test section

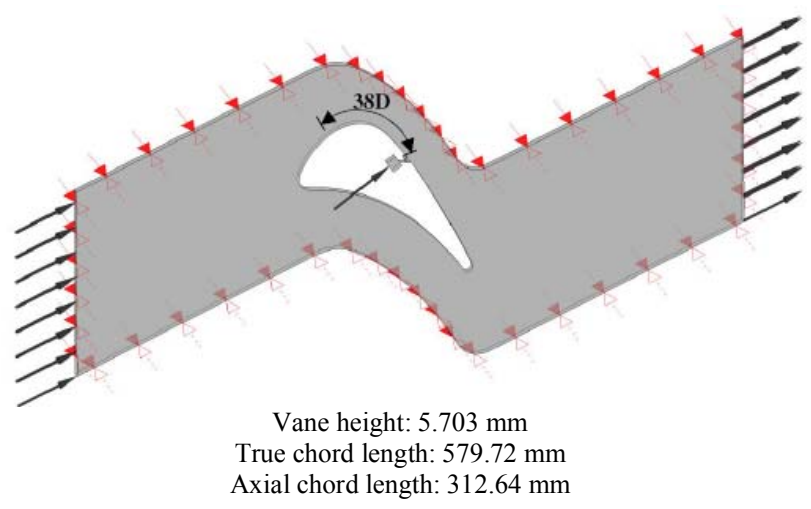

Figure 2 A view of computational domain

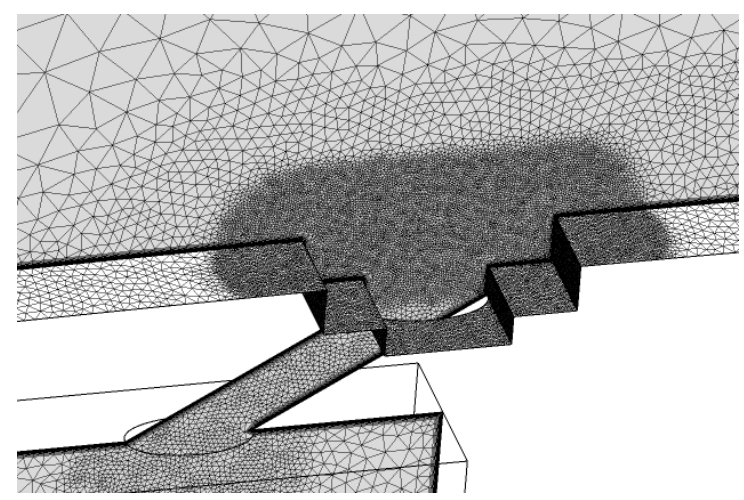

Figure 3 Computational grid for multi trench

TABLE I SIMULATION PARAMETER CONDITIONS

\begin{tabular}{|l|l|}
\hline $\boldsymbol{D}$ & $4.11(\mathrm{~mm})$ \\
\hline $\boldsymbol{\alpha}$ & $30^{\circ}$ \\
\hline \multirow{2}{*}{$/ \boldsymbol{D}$} & 4.1 (with trenches) \\
\cline { 2 - 2 } & 6.7 (without trenches) \\
\hline $\boldsymbol{P} / \boldsymbol{D}$ & 2.775 \\
\hline $\boldsymbol{S} / \boldsymbol{D}$ & 0.5 and 0.8 \\
\hline $\boldsymbol{D} \boldsymbol{R}$ & 1.3 \\
\hline $\boldsymbol{W} / \boldsymbol{D}$ & $4 \mathrm{D}$ and $2 \mathrm{D}$ \\
\hline $\boldsymbol{M}$ & $0.5: 3$ \\
\hline Mainstream conditions \\
\hline $\boldsymbol{T} \boldsymbol{u}$ & $1 \%$ \\
\hline $\boldsymbol{A} / \boldsymbol{D}$ & 0.42 \\
\hline $\boldsymbol{U} \infty$ & $30.82(\mathrm{~m} / \mathrm{s})$ \\
\hline $\boldsymbol{T}$ & $300(\mathrm{~K})$ \\
\hline Coolant conditions \\
\hline $\boldsymbol{T} \boldsymbol{u}$ & $2 \%$ \\
\hline $\boldsymbol{A} / \boldsymbol{D}$ & 0.56 \\
\hline $\boldsymbol{T}$ & $230.77(\mathrm{~K})$ \\
\hline
\end{tabular}

All flow inlets were defined as velocity inlets, while the outlet was defined as a pressure outlet. Due to symmetry, the model was cut along its half-plane and a symmetry boundary condition was applied. The left side was assigned walls with free slip conditions. All remaining plane were assigned adiabatic walls with no slip conditions. Air was taken as a working fluid, since density variation is significant over this temperature range; the density was modeled as a function of temperature according to the following equation:

$$
\rho=\frac{P}{R * T}
$$

where, $\mathrm{P}$ is the reference pressure $(101325 \mathrm{~Pa}), \mathrm{R}$ is gas constant $\left(287 \mathrm{~J} \mathrm{~kg}^{-1} \mathrm{~K}^{-1}\right)$. The plenum inlet velocity was varied to simulate different blowing ratios. The temperature was set to $230.77 \mathrm{~K}$ to obtain a density ratio of $\mathrm{DR}=1.3$.

\section{RESULTS}

In the present work, the center line and lateral average adiabatic film effectiveness were investigated at different blowing ratios depending on operating conditions as shown in Table 1. Contours and thermal profiles were drawn.

For multi trench with two steps heights $0.5 \mathrm{D}$ and $0.8 \mathrm{D}$, centerline and lateral averaged adiabatic film effectiveness as 
a function of dimensionless downstream distance with varying blowing ratios $(0.5: 3)$ at density ratio of 1.3 are shown in Fig.4 and Fig. 5.It can be seen from these figures that the adiabatic film effectiveness increased from maximum at hole exit and reduced with of dimensionless downstream distance. At increasing the blowing ratio, the adiabatic effectiveness increased without separation over the vane surface. The lateral adiabatic film effectiveness increased from 1 at hole exit and reduced to $0.127,0.207,0.3199,0.436$, and 0.3917 at $S / D=15$ and reduced to $0.02254,0.02805,0.03689$ and 0.05124 at $\mathrm{X} / \mathrm{D}$ $=34.4$, then the values fixed at $\mathrm{S} / \mathrm{D}=47.4$ to become 0.02162 , $0.02654,0.03374$ and 0.04451 at $\mathrm{M}=0.5,1,2$, and 3, respectively.

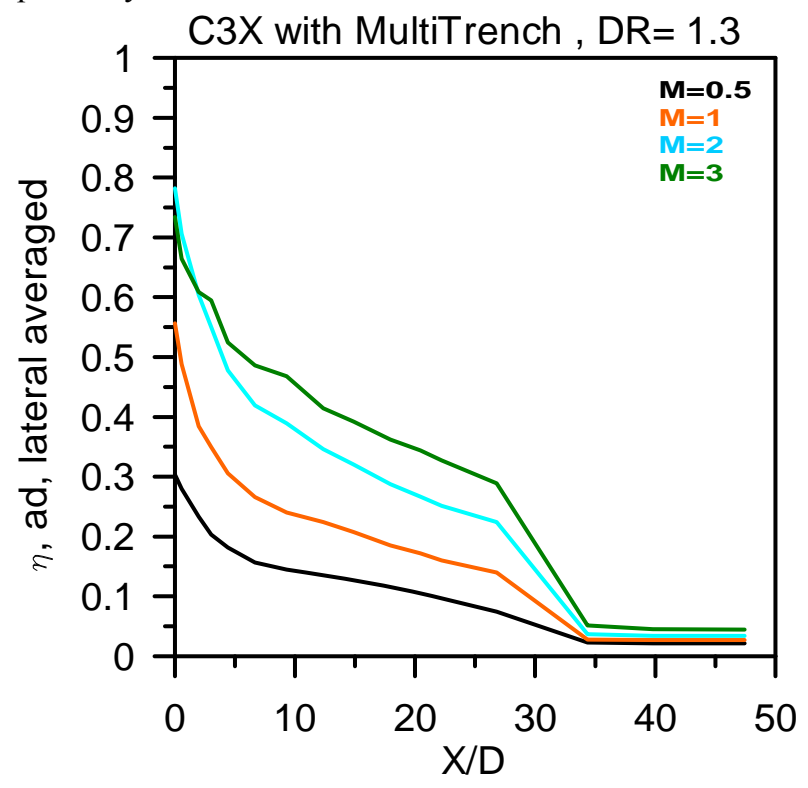

Figure 4 Lateral averaged adiabatic film effectiveness

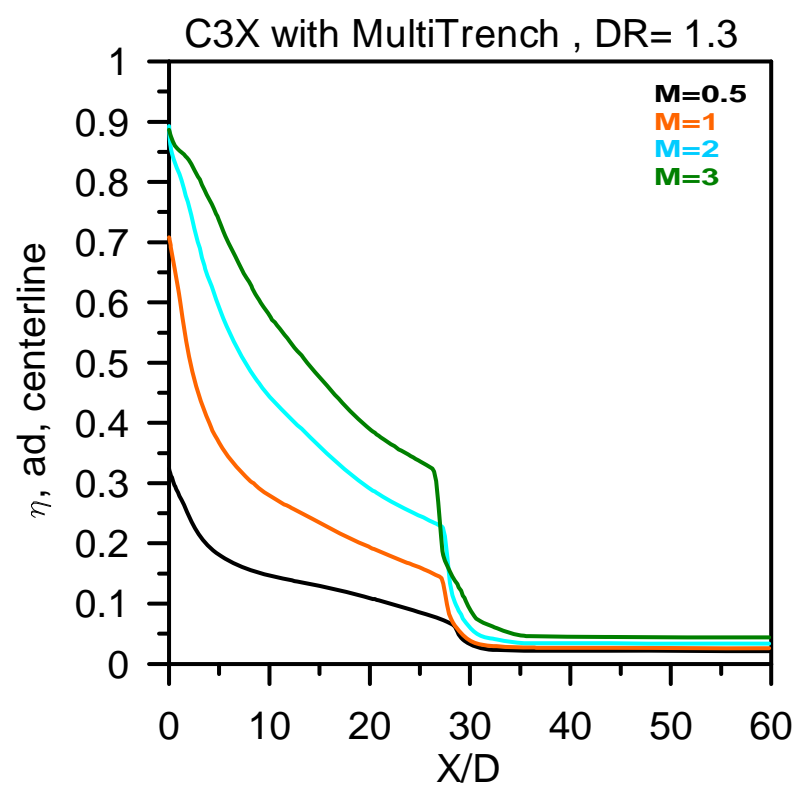

Figure 5 Centerline adiabatic film effectiveness

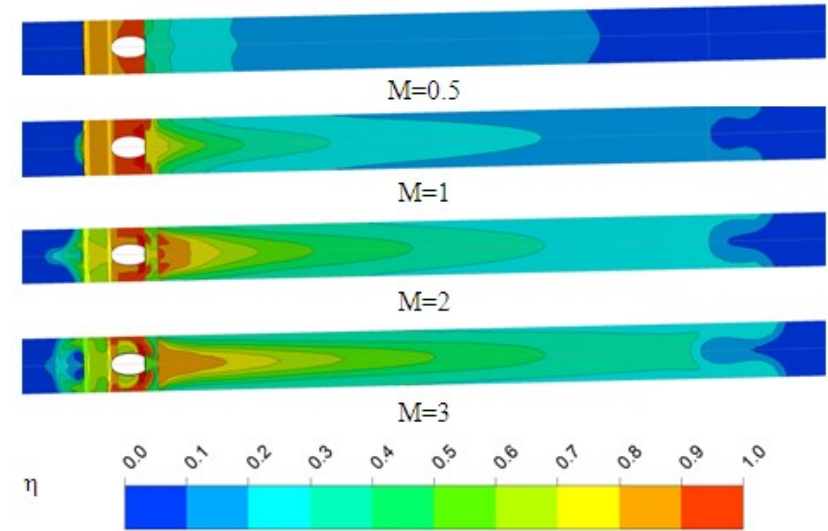

Figure 6 Film effectiveness distributions over vane surface

Fig. 6 explains film effectiveness distributions for multi trench with varying blowing ratios over vane. The coolant enters a shallow $(0.5 \mathrm{D})$ and narrow trench $(2 \mathrm{D})$ before mixing with the mainstream. It appears that the coolant exiting the holes develops sideways and fills the narrow trench before exiting as a more two-dimensional film. Where the jet exits the cylindrical hole and slows down as it enters the trench due to the area increase and exits out of the trench at a much lower velocity. Then the coolant enters medium depth (0.8D) and wide trench (4D) to enhance the coverage distance and decrease the jet velocity another time indicating that the jet will have a lower momentum and thus will tend to stay closer to the surface. Outside the multi trench, the effectiveness will decrease gradually due to mixing with the mainstream. At increasing blowing ratios, the jet becomes strong and the mainstream can not penetrate this cover. Then, the film effectiveness increases in lateral and stream wise directions.

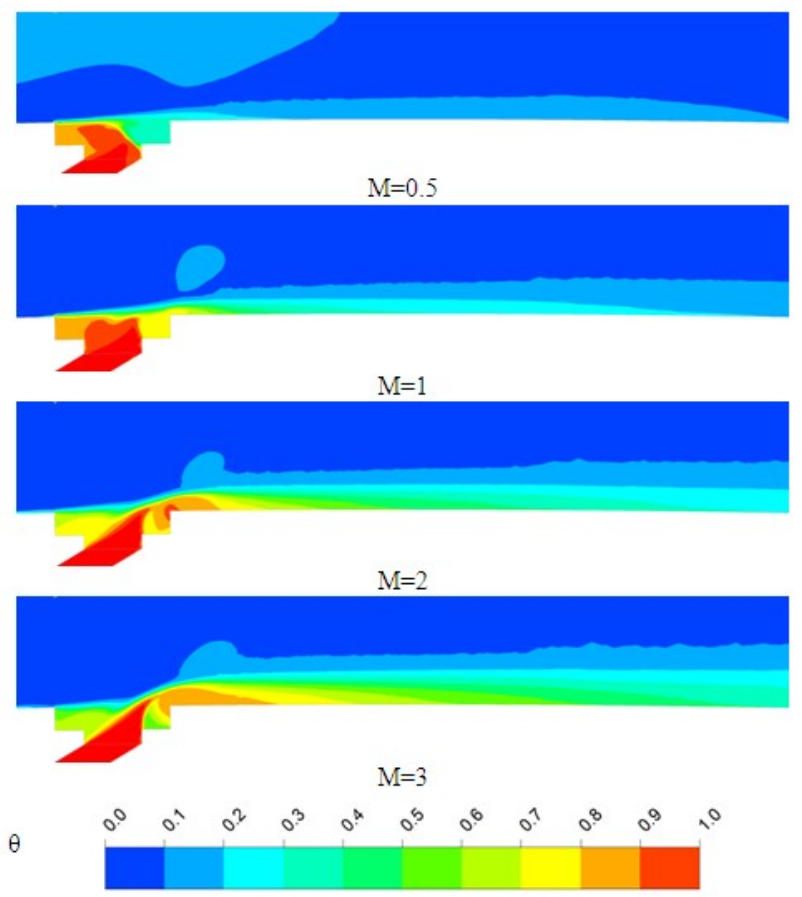

Figure 7 Centerline thermal profiles for multi trench 
Fig. 7 presents centerline thermal profiles for multi trenches at various blowing ratios. The downstream edge of the jet interacts with the trench edge and pushes coolant toward the upstream side resulting in a larger displacement of the mainstream from the surface forming recirculation zone on the upstream edge of the trench. This recirculation zone is small or large depending on blowing ratios. At low blowing ratios, small recirculation inside the trenches prevents the mainstream to enter the trenches zone. At high blowing ratios, larger recirculation zones at upstream wide trench edge pushes the mainstream outside the trenches. It's clear that at increased blowing ratios, the jet momentum and spreading increased in three dimensions maintaining on the attachment with surface.

\section{CONCLUSIONS}

In this study, computational simulations were made using ANSYS CFX to predict the improvements in film cooling performance for multi trench configurations. The effects of blowing ratios on adiabatic film effectiveness are analyzed in detail. From the computational results, the following conclusions can be drawn:

- By using the multi trench configuration, the coolant jet impacted the trench wall two times allowing increasing the spreading of coolant laterally in the trench, reducing jet velocity and jet completely covered on the surface.

- No mainstream entrainment inside multi trench at $\mathrm{M}=0.5: 3$.

- The results indicate that this configuration increased adiabatic with increasing blowing ratios and no observed film blow-off at all blowing ratios
- This study has shown the usefulness of CFD simulations to screen various film cooling configurations and identify promising geometries to be studied experimentally. This could greatly save manufacturing and experimentation time and cost.

\section{REFERENCES}

[1] Y. Lu, A. Dhungel, S. V Ekkad., and R.S. Bunker, "Effect of trench width and depth on film cooling from cylindrical holes embedded in trenches" ASME Journal of Turbo machinery, Vol. 131, pp. 1-13. 2009

[2] R. Bunker, "Film cooling effectiveness due to discrete holes within a transverse trench", ASME paper GT2002-30178, 2002.

[3] S. Waye and D. Bogard, "High resolution of film cooling effectiveness measurements of axial holes embedded in a transverse trench with various trench configurations", ASME Paper GT2006-90226, 2006.

[4] Y. Lu, , H. Nasir, and S. V. Ekkad, , "Film cooling from a row of holes embedded in transverse slots", ASME Paper GTI2005-68598, 2005.

[5] K. L. Harrison, and D. G. Bogard, "CFD predictions of film cooling adiabatic effectiveness for cylindrical holes embedded in narrow and wide transverse trenches", ASME Paper GT2007-28005, 2007.

[6] L. Jia, , R. Jing, and J. Hongde, "Film cooling performance of the embedded holes in trenches with compound angles", ASME Paper GT2010-22337, 2010.

[7] H. A. Zuniga and J. S. Kapat, "Studied effect of increasing pitch-todiameter ratio on the film cooling effectiveness of shaped and cylindrical holes embedded in trenches", ASME Paper GT2009-60080, 2009.

[8] J. E. Albert and D.G. Bogard, "Measurements of adiabatic film and overall cooling effectiveness on a turbine vane pressure side with a trench", ASME Paper GT2011-46703, 2011.

[9] L.D. Hylton, M.S. Milhec, E.R. Turner, D.A. Nealy, and R.E. York, "Analytical and experimental evaluation of the heat transfer distribution over the surfaces of turbine vanes", NASA CR 168015, 1983. 